\title{
El reto de la poesía gráfica: análisis de la obra de Begoña García- Alén
}

\section{The challenge of graphic poetry: análisis of the work of Begoña García-Alén}

TIPO DE TRABAJO: comunicación.

\author{
PALABRAS CLAVE \\ Poesía gráfica, Cómic, Cómic Abstracto, Begoña García-Alén
}

KEY WORDS

Graphic Poetry, Comic, Abstract comic, Begoña García-Alén

RESUMEN

La poesía gráfica se ha consolidado en los últimos años como uno de los campos de experimentación del cómic más activo y fructífero. La exploración de las posibilidades del cómic alejadas de la tradicional narratividad secuencial ha permitido entroncar la narración visual con la poesía concreta y caligramática, encontrando una relación cuya naturalidad y potencialidad resulta sorprendente (McHale, 2010). Aunque las primeras experiencias de la poesía gráfica pueden ser rastreadas en la obra de George Herriman y en la fundacional Poema en viñetas de Dino Buzzatti, en la última década se ha producido un desarrollo espectacular desde el espacio de libertad que representa la autoedición y el fanzinismo. Autores y autoras como Bianca Stone, Warren Craghead o Tom Hart han marcado un camino que en España ha sido seguido por una activa generación de jóvenes autores y autoras entre los que destacan Cynthia Alfonso, Klari Moreno, Julia Huete, María Medem, Óscar Raña, Begoña García-Alén, Andrés Magan o Roberto Masso, entre otros. En este trabajo, analizaremos la obra de García-Alén (Pontevedra, 1989), estudiando la evolución que se ha producido desde sus primeras publicaciones autoeditadas en su sello Noche Liquida, como Lujo Infinito (2015), La máscara de oro (2016), Orden y Forma (2016), Unha Gran Dama (2017) y Nueva Mística de Vigo (2018), a las publicadas por editoriales alternativas, como Perlas del Infierno (Fosfatina, 2014) o Nuevas estructuras (Apa Apa Cómics, 2017). Nos centraremos especialmente es esta última, examinando sus estrategias de narración visual a través del simbolismo, la composición espacial y cromática y el montaje analítico como estructura temporal interna de la página.

\section{ABSTRACT}

Graphic poetry has been consolidated in recent years as one of the most active and fruitful experimental fields of comics. The exploration of the possibilities of comic stripped away from the traditional sequential narrative has allowed to connect the visual narrative with concrete and caligrammatic poetry, finding a relationship whose naturalness and potential is surprising (McHale, 2010). Although the first experiences of graphic poetry can be traced in the work of George Herriman and in the foundational Poem in vignettes by Dino Buzzatti, in the last decade there has been a spectacular development from the space of freedom that represents self-publishing and fanzinism. Authors such as Bianca Stone, Warren Craghead and Tom Hart have marked a path that in Spain has been followed by an active generation of young authors including Cynthia Alfonso, Klari Moreno, Julia Huete, Maria Medem, Óscar Raña, Begoña García-Alén, Andrés Magan or Roberto Masso, among others. In this work, we will analyze the work of García-Alén (Pontevedra, 1989), studying the evolution that has occurred since his first self-published publications on his label Noche Liquida, such as Lujo Infinito (2015), La máscara de oro (2016), Orden y forma (2016), Unha Gran Dama (2017) and Nueva Mística de Vigo (2018), to those published by alternative publishers, such as Perlas del infierno (Fosfatina, 2014) or Nuevas estructuras (Apa Apa Comics, 2017). We will focus especially on the latter, examining their strategies of visual narration through symbolism, spatial and chromatic composition and analytical montage as the internal temporal structure of the page. 


\section{INTRODUCCIÓN}

La poesía gráfica se ha consolidado en la última década como un campo de experimentación de nuevas vanguradias y posibilidades expresivas del lenguaje del cómic, en un rápido desarrollo que, si bien hunde sus raíces en la poesía concreta y caligramática, así como en obras previas donde el lenguaje del cómic ha encontrado correlato con el de la poesía, ha tenido en los últimos años una definición más clara y decidida a partir del trabajo de una nueva generación de autores. En este trabajo se definen las claves de esta nueva forma del lenguaje del cómic, constituida de forma paralela como movimiento creativo, a través del análisis de la obra de una de las autoras que más lo ha desarrollado: Begoña García-Alén.

\section{METODOLOGÍA}

Se ha desarrollado un análisis previo del desarrollo de la poesía gráfica en el lenguaje del cómic, con revisión bibliográfica de los estudios que se están desarrollando en el ámbito de la historieta, todavía limitados por la limitación de publicaciones especializadas en este ámbito. Los resultados obtenidos se han utilizado como base para el análisis de la obra de la autora García-Alén, de la que de ha hecho seguimiento de su obra para comprobar la evolución estilística, desarrollando una lectura comentada de sus dos últimas obras para fijar los posibles estilemas que ha establecido en su sistema expresivo.

\section{DESARROLLO}

\section{Hacia una traslación de la poesía al cómic}

De forma natural parece asumirse que la narrativa del cómic se establece desde una linealidad procedente de narración en prosa literaria y que, por lo tanto, las concomitancias con la literatura son obvias. Sin embargo, la dinámica espacial y el ritmo narrativo que proporciona la composición gráfica de la página y los desbordes que se pueden hacer de ella puede ser fácilmente relacionados con la rítmica de la poesía, por lo que no pocos autores y autoras han planteado también la posibilidad de desarrollar una auténtica poética gráfica. La traslación de la definición más convencional de la poesía al cómic es relativamente sencilla: una expresión de la belleza a través de la imagen con un ritmo propio.

Ya en los primeros años de la historieta se investiga esta línea creativa, cuando aparecen obras que evitan un storytelling derivado de la cadencia secuencial lineal y aprovechan las opciones narrativas que da una página en blanco. Autores como George Herriman rompen con el concepto tradicional de la página y del ritmo de lectura, buscando establecer líneas de flujo de lectura propias que pueden ser emparentadas con la ruptura espacial de la forma tradicional lineal de lectura que establece la poesía caligramática. No es difícil establecer relaciones entre la investigación poética que se desarrolla en los caligramas o la evolución de la poesía concreta hacia formas de poesía visual, donde la creación deja de ser un objeto para ser leído y pasa a ser un objeto creado para "ser visto" (Bohn, 2013). Esa línea establece su grado de evolución en el uso consciente de la palabra como elemento básico, como puede darse en los caligramas de Apollinaire, a la definitiva integración de texto e imagen que plantea la obra de autores como Carl André, donde la forma visual no es un refuerzo de la palabra, del texto escrito, sino que adquiere protagonismo propio, constituyéndose como paratexto esencial de la lectura y entroncando la poesía como un arte visual (Collins, 2013). Sin embargo, estos movimientos que se desarrollan durante las primeras décadas del siglo XX no encuentran un paralelo inmediato en el cómic, todavía inmerso en ese momento en un proceso de autoidentificación que lo alejara de una consideración infantil y juvenil, pero no deja de resultar sintomático que una de las primeras obras que analizan las posibilidades del cómic como medio adulto, sea precisamente una que establece las primeras correlaciones entre la poesía y el cómic: Poema a fumetti, de Dino Buzzatti ${ }^{1}$. La obra de Buzzatti (fig.1) nace precisamente tras los primeros intentos de establecer un estudio sistemático del cómic desde perspectivas semiológicas, empujadas tanto desde Italia con el llamado "grupo de Bordighera" (formado en 1965 por los estudiosos Claudio Bertieri, Luis Gasca, Umberto Eco y Romano Calisi) y los trabajos que desde Francia realizaba el CELEG (Centre d'études des littératures d'expression graphique) de Francis Lacassin, Alain Resnais y Évelyne Sullero. Buzzatti reescribe el mito de Orfeo y Eurídice desde una perspectiva moderna a través del erotismo y la música, con grandes viñetas de una página que incorporaban texto creando una unidad que actúa como verso del poema. Para Buzzatti, el dibujo cumple dos funciones principales: por un lado, una pasiva donde el dibujo es simplemente una ilustración del texto; por otro, la activa, donde el simbolismo gráfico extiende la interpretación del texto hacia una nueva lectura.

\footnotetext{
${ }^{1}$ Editado por primera vez en 1969, en Italia, por la Editorial Mondadori.
} 


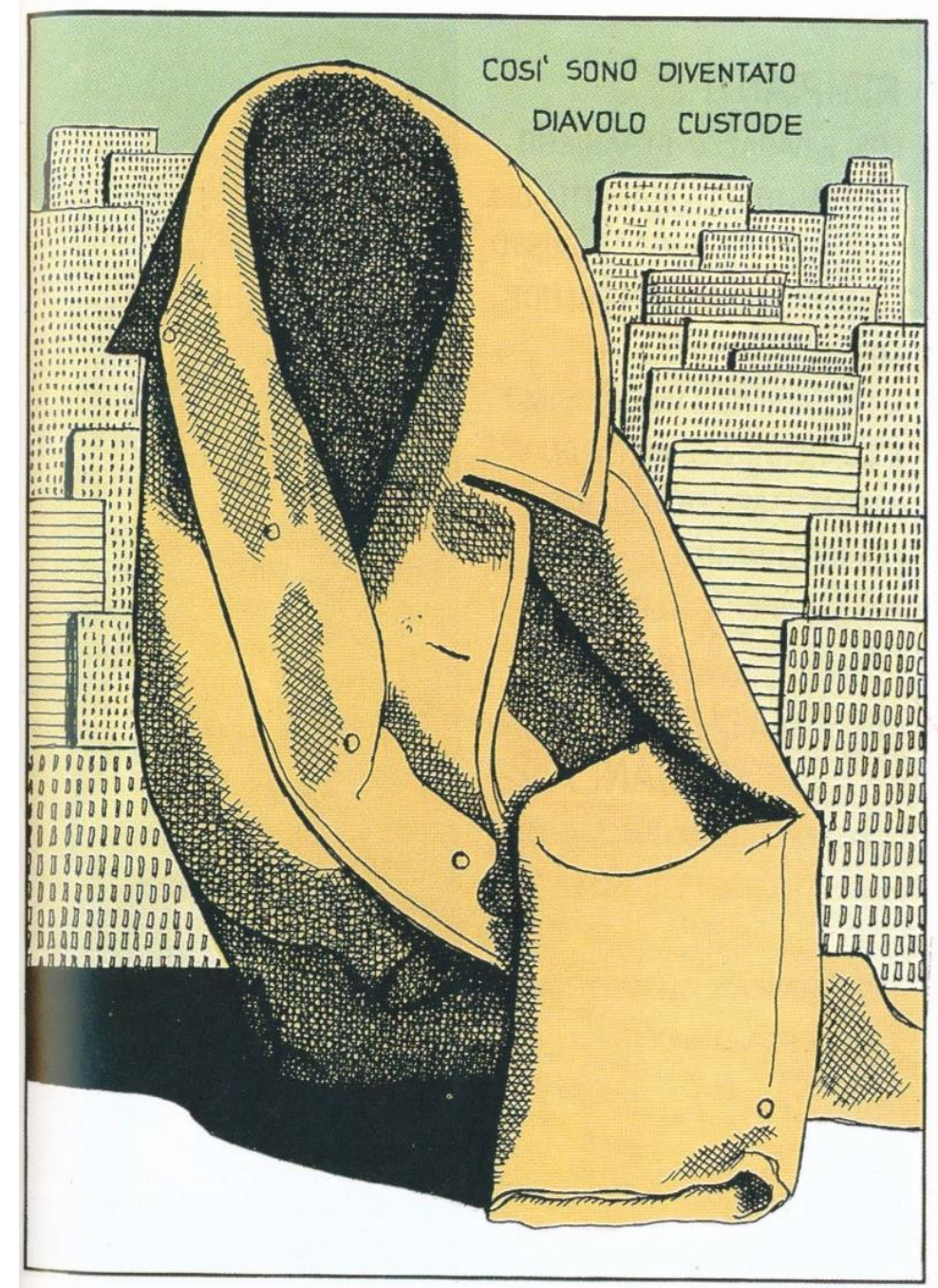

Figura 1: Página de Poema a fumetti, de Dino Buzzatti.

Este uso del cómic como elemento participante de la experiencia poética, que lo aleja de la función narrativa asociada tradicionalmente a la historieta ha sido especialmente estudiada en los primeros años del siglo XXI, con la aparición de una serie de autores que, de forma consciente, buscan igualar la experiencia poética de la palabra con otra conseguida a través del dibujo, extendiendo su función narrativa a la poética aprovechando los recursos gráficos. Por ejemplo, como establece Brian McHale (2010), la segmentación poética tiene un análogo directo en la separación natural que establece la viñeta en la secuencia, ya sea espacial o temporal. El espacio en blanco, el gutter, actúa como elemento nuclear que transforma la secuencia en narración única:

The gutter plays host to much of the magic and mystery that are at the very heart of comics. Here in the limbo of the gutter, human magination takes two separate images and transforms them into a single idea. (McCloud, 1993)

Sin embargo, esta separación es, también, un límite que puede establecer un ritmo lineal para el poema, disolviendo cualquier intento de abstracción poética (Calligaro, 1986). De hecho, la dificultad de huir de la hegemonía de la narración con viñetas parece hacer prácticamente imposible ese ejercicio de abstracción. Sin embargo, las posibilidades creativas del cómic rompen esa imposición para encontrar una salida que lleva a la experimentación formal donde la abstracción es posible desde el aprovechamiento de los recursos visuales de la historieta, como Baetens afirma que "a priori approach to narrative in comics as a mere instantiation of narrative, in general is now under pressure" (Baetens, 2011). De hecho, la posibilidad de la abstracción en el cómic ya no se estudia como una posibilidad remota, sino como un hecho establecido (Molotiu, 2009). 
Autores como Bianca Stone, Warren Craghead, Joh Hankiewicz o Tom Hart experimentan con el cómic para acercarse a la expresividad poética, dejando que el dibujo focalice el protagonismo y genere un ritmo visual propio, creando una corriente de contenido a partir de los elementos gráficos que deben ser interpretados por el lector.

Para Tamryn Bennet (2014),

Just as a reader must employ different reading techniques with poetry and prose, comics-as-poetry must be read the same way, with attention to the visual cues that interact with text or act on their own adding an additional layer of complexity. Poetry provides a narrative as much as any other art form does, and likewise, the comics analyzed below are examples of comics-as-poetry that offer a very rich, complex and mysterious kind of narrative that, like poetry, requires the engagement of the reader.

La aparición de estas experiencias desde el campo de los minicomics y de la novela gráfica ha dado también a no pocos debates que afectan incluso a la propia denominación: la identificación de la novela gráfica como una derivación de la narrativa literaria choca frontalmente con la aceptación de la no narratividad inherente a la poesía, por lo que existen diferentes aproximaciones a su nomenclatura: mientras que algunos autores hablan abiertamente de graphic poem (Badam, 2012), poetry comics (Dueben, 2012), graphic poetry (Surdiacourt, 2012) o comic-as-poetry (Clough, 2009), para la investigadora Tamryn Bennett, la opción más acertada sería "comics poetry":

For me, however, the term 'comics poetry' more accurately foregrounds the origins of the form within the field of comics rather than graphic novels. for sequential narrative means. (Bennett, 2014)

Esta identificación del cómic con la poesía es avalada por Brian McHale (2010), que afirmaría:

[...]comics appear to be more akin to poetry, even to prestigious avant-garde poetry, than we might have supposed.

El cómic se establece como una nueva herramienta de desarrollo para la poesía a través del dibujo, que aprovecha una lectura más densa de la viñeta a través de los elementos visuales, desarrollando un flujo visual no estrictamente narrativo a partir de elementos que pueden ser identificados tanto con la abstracción como con el simbolismo. En España, en los últimos años se ha dado un fuerte impulso a la experimentación en el cómic, con una generación de autores y autoras que entra directamente en la investigación de las posibilidades expresivas del cómic desde una interpretación de vanguardia estética que ha encontrado en la poesía gráfica una forma natural de dar salida a sus inquietudes creativas. Artistas como Enrique Cabezón, Cynthia Alfonso, Julia Huete, Los Bravú, José Jajaja, Oscar Raña o Begoña García Alén realizan obras de gran riesgo formal donde la expresión poética y la abstracción formal se estructuran como ejes de su creación².

\section{La insurgencia de la poesía gráfica de Begoña García-Alén}

De este grupo de autores y autoras resulta especialmente interesante el caso de Begoña García-Alén (Pontevedra, 1989). Su obra comienza a aparecer en fanzines como el colectivo Firecream (2010-14), que autoedita junto a Andrés Magán, donde ambos autores ya avanzaban su interés por la experimentación formal más allá de la provocación natural del fanzine. Los 8 números de esta publicación sirven además como presentación de una nueva escena gallega a la que haya que añadir los nombres de Arturo Mosquera, Berto Fojo, Irene Vidal, Pepa Prieto Puy, Roberta Vázquez, Roberto Massó, Santi Zubizarreta, Santiago Paredes o Teresa Ferreiro, que conformarán un colectivo fundamental en la exploración del lenguaje del cómic por el terreno de la abstracción y la poesía gráfica durante la segunda década del siglo XXI en el cómic español.

La obra de García-Alén comenzó a interesarse en el minimalismo gráfico y la exploración la de no narratividad a través de la abstracción gráfica y el uso de elemento inorgánicos, en la línea de los planteamientos de cómic abstracto analizado por Molotiu (2009). La recopilación Perlas del Infierno (Fosfatina, 2014), recoge esa rápida evolución de la autora a través de una propuesta de historietas mudas donde el movimiento es el eje central que conecta las historias. Fanzines autoeditados posteriores en su sello Noche Liquida, como Lujo Infinito (2015), La máscara de oro (2016), Orden y Forma (2016) o Unha Gran Dama (2017), ahondan en esa indagación sobre la posibilidad expresiva puramente sensorial de la composición gráfica, a través tanto del color como de la composición, que serán fundamentales para el salto a una obra de mayor ambición: Nuevas estructuras (Apa Apa Cómics, 2017).

\footnotetext{
2 Hay que destacar el trabajo en este campo de la editorial gallega Fosfatina, que se ha especializado en la publicación de obras de gran resgo formal, con la poesía gráfica como eje de las publicaciones. Un ejemplo de este trabajo es la antología Hoodoo Voodoo (Vigo: Fosfatina, 2016).
} 


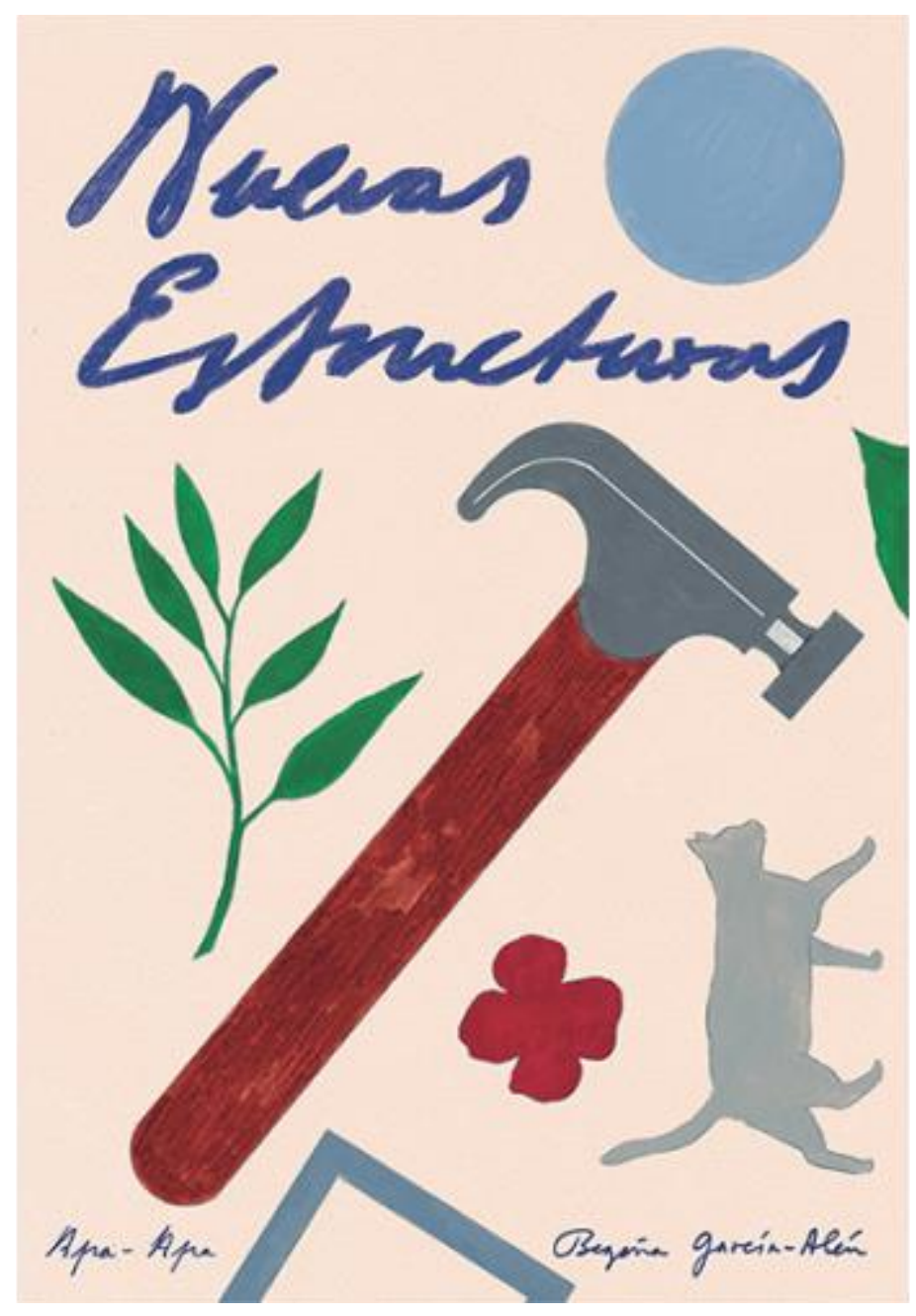

Figura 2. Portada de Nuevas Estructuras, de Begola García-Alén (Apa Apa Cómics, 2017)

En esta obra, se puede encontrar ya la configuración de un auténtico sistema expresivo de la autora, con una serie de estilemas propios que definen plenamente su trabajo. En Nuevas estructuras una desconocido cuenta en primera persona la llegada a una casa donde se desarrollará un proyecto arquitectónico, punto de partida de un paseo por el proceso desde esa perspectiva anónima, pero que representará el único punto de empatización del lector. En el primer capítulo, La casa, se presentan ya constantes fundamentales del trabajo de la autora, como la utilización de una división de página tradicional en viñetas (6, 8 o 9 en el primer capítulo), contrapuesta con una distribución espacial que recoge un montaje analítico en el que solo se representan objetos, evitando conscientemente la representación humana. El texto, siempre en caja aparte, al estilo de las primeras narraciones gráficas, es austero, marcando un ritmo propio de lectura para las imágenes que lo envuelven. Sirva de ejemplo la página 6 , donde la salida hacia el nuevo destino es simplemente insinuada con elementos aislados de ese proceso: la maleta, la ventana, la puerta del coche, un círculo que representa la rueda en movimiento y un trazo caótico para simbolizar el camino, que a su vez se interrelaciona con el texto que acompaña esa viñeta para conectar con el pasado del narrador/a. La llegada a la casa y la posterior exploración de la misma siempre se hará desde esa metodología, creando un juego de elementos inspirativos desde lo inorgánico y el fragmentarismo de sensaciones discontinuas, creando una tensión entre los elementos: el relato pausado del texto crea sus propios ritmos e interpretaciones, frente a los constitutivos gráficos, que articulan su dinámica interna. La abstracción aparece por momentos, pero se equilibra con una aparición inesperada: siluetas humanas, referentes de un equipo de trabajo que llega a ayudar en el proyecto y que aparecerán recurrentemente como figuras fantasmales, solo perfiladas en silueta. Durante el siguiente capítulo, El proyecto, García-Alén introduce nuevos elementos simbólicos: la construcción de casas de pájaros como simbolismo de la edificación para humanos, el encarcelamiento de la libertad que da seguridad, desarrollado mediante sugerentes imágenes alegóricas a partir de herramientas y planos de arquitectónicos, formando lo que Harguindey (2017) define como una "serie decorativa". Un ritmo establecido que se romperá en el tercer capítulo, El sueño, que desarrolla un episodio onírico donde los elementos inorgánicos se van a presentar junto a otros puramente abstractos: formas geométricas y de color (en la línea de trabajos previos como la serie El espectador en la página web Tik Tok Comics, o fanzines previos autoeditados como Lujo infinito), que junto al uso de palabras que pierden su significado 
literario para convertirse en objetos visuales a través del tratamiento tipográfico, consiguen trasladar al lector una experiencia visual de surrealismo puro, pero fuertemente inspirada en las imágenes que se han ido desarrollando previamente. En el último capítulo, La construcción, la autora planteará un enfrentamiento entre los conceptos de construcción y destrucción, la labor artificial del humano anónimo y fantasmal frente a la realidad de una naturaleza presente y viva. El uso de grandes viñetas a toda página es especialmente interesante: el estatismo del escenario es roto por una ventana por la que se puede ver el trabajo de los operarios, representados como sombras proyectadas que transforman la habitación en nueva encarnación de la caverna platónica.

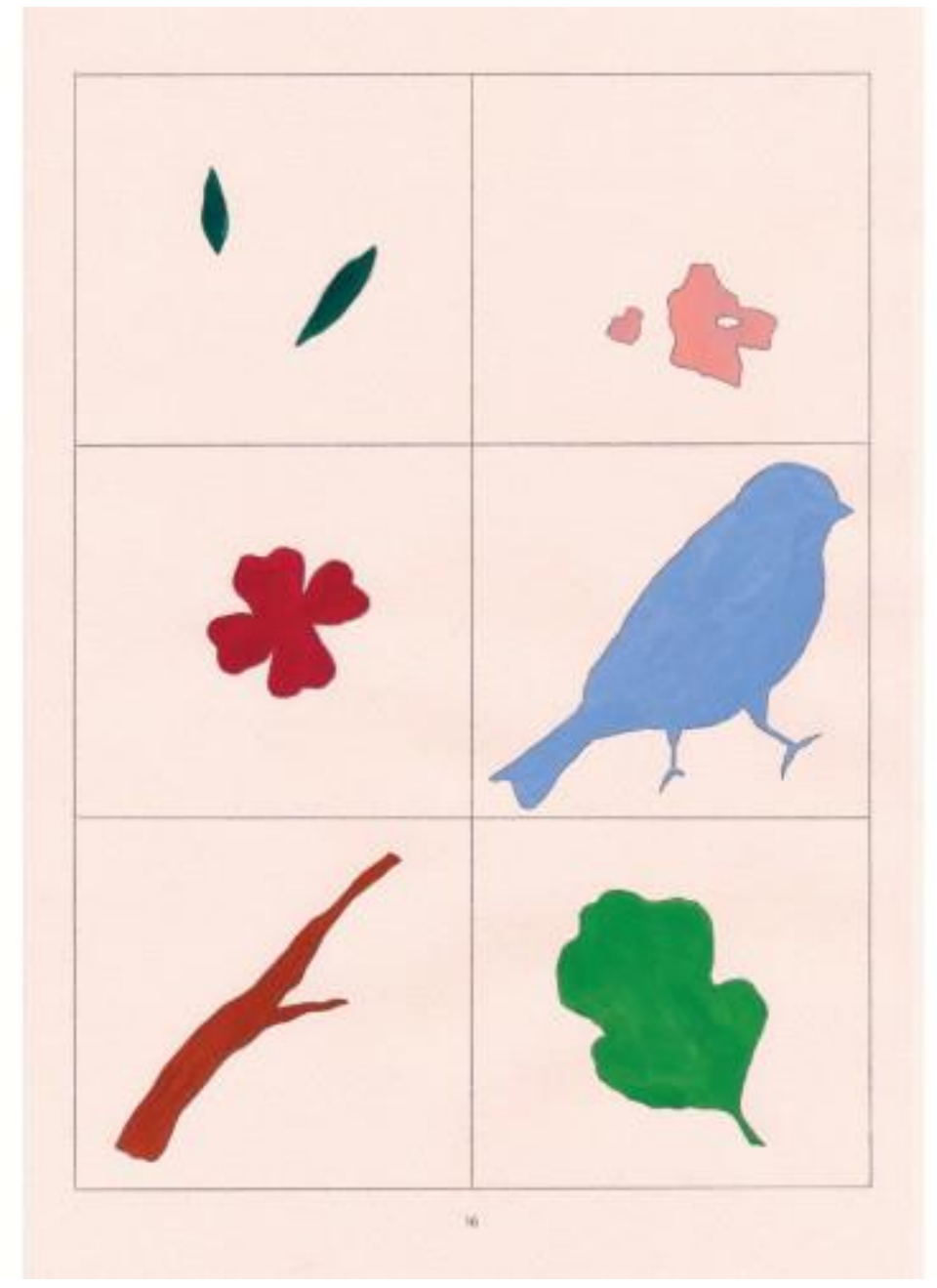

Figura 3. Página de Nuevas Estructuras, donde se observa el montaje analítico de elementos aislados.

De alguna manera, la lectura de Nuevas estructuras genera en el lector dos experiencias muy diferenciadas: una primera, puramente contemplativa, como testigo mudo de la construcción y destrucción de una idea, con múltiples lecturas más allá de la contemplativa (Vilches, 2017). Una segunda, soterrada, en la que los capítulos se mimetizan con la propia construcción de una lectura: la presentación, desarrollo, disfrute y posterior análisis desconstructivo puramente derridiano de la obra son claramente equiparables a la división capitular de la obra de García-Alén.

En su última obra autopublicada, Nueva Mística de Vigo (2018), ilustra los poemas de Juan Fernández Navazas. Sin embargo, la relación entre el poema escrito y el poema gráfico va mucho más allá de la simple ilustración o adaptación simbólica: García-Alén plantea un diálogo entre historias a lo largo de los cinco bloques que componen el libro, estableciendo un juego de lectura y contralectura, de construcción y deconstrucción. Cada bloque, inspirado lejanamente por la experiencia personal biográfica del escritor, es reinterpretado por García-Alén como una reflexión visual que aporta un flujo de sensaciones y sentimientos que la palabra no puede desarrollar. Impactos visuales en blanco y negro rotundo, que se basan en las mismas claves narrativas que se vieron en Nuevas Estructuras. La estética de esa modernidad de "lo nuevo", se diluirá en el primer bloque con la evocación del Antiguo Egipto, 
que se representa tanto desde la aportación científica de la arqueología como desde lo imaginado, representando en una última historieta el paso del tiempo desde lo desaparecido, desde lo olvidado e inundado por la arena.

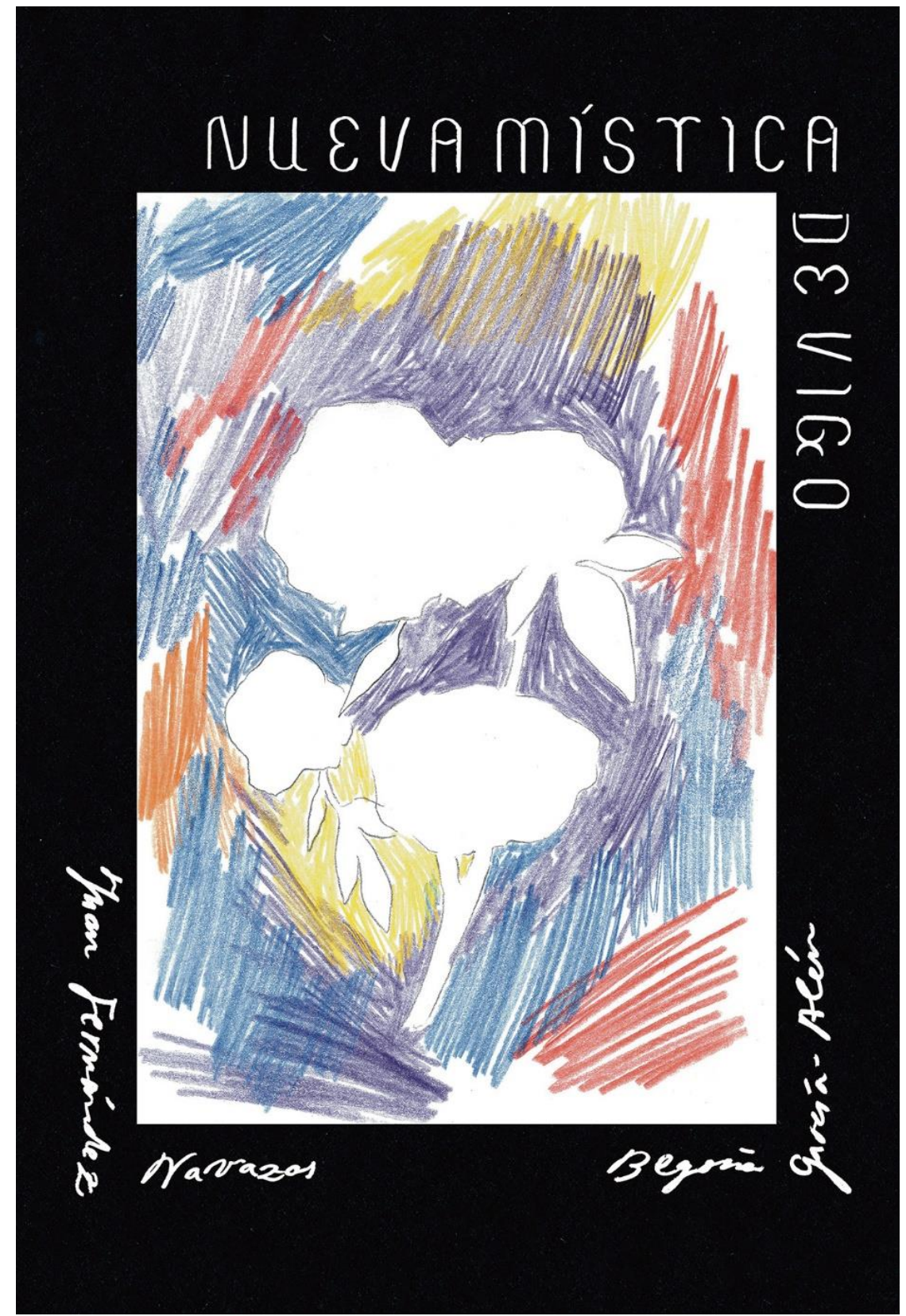

Figura 4. Portada de Nueva Mística de Vigo (Noche Líquida, 2018).

En los diferentes bloques la autora experimentará con la representación simbólica de la pobreza y la soledad a través del montaje analítico de elementos aislados de lo que el lector reconstruirá como una historia completa desde la sugerencia minimal; con la cinética pura desde la influencia evidente de la obra de Yuichi Yokoyama ${ }^{3}$ en La máquina; o con el análisis del paso de la historia a partir de un elemento coincidente, una ruptura geométrica, que establece conexiones temporales a partir de la ausencia y el vacío, del contexto de la forma.

\footnotetext{
${ }^{3}$ Yokoyama desarrolla su obra alrededor de la cinética de la imagen y el movimiento continuo en paisajes industriales donde la máquina alza su protagonismo para invadir lo humano y transformarlo. Pepo Pérez, Neo Manga for post-humans, Mincho, 6, 87-91 (2014)
} 


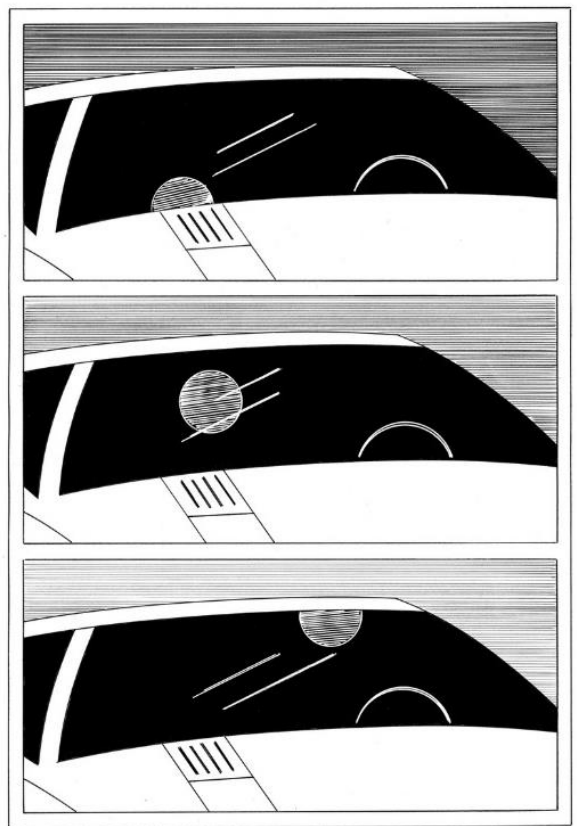

91

Figura 5: Página de La Máquina, en Nueva Mística de Vigo (Noche Líquida, 2018)

\section{CONCLUSIONES}

La poesía gráfica se ha constituido ya como forma determinante del cómic moderno, que explora las posibilidades expresivas de la no narratividad en el cómic, desde la abstracción y la evocación desde la imagen. Begoña García-Alén es la autora que más ha desarrollado las posibilidades de este nuevo movimiento en nuestro país, a través de un estilo propio basado en la mixtura de elementos de abstracción con el establecimiento de ritmos de lectura particulares basados en el montaje analítico y el minimalismo gráfico, focalizados en la fuerza de los objetos inorgánicos.

\section{FUENTES REFERENCIALES}

Badman, D. (2012). Comics Poetry, Poetry Comics, Graphic Poems. Recuperado el 1 de febrero de 2019, de http://hoodedutilitarian.com/2012/08/comicspoetry-poetry-comics-graphic-poems/

Baetens, J. (2011). Abstraction in Comics. Substance, 40 (1), 94-113.

Bennet, T. (2014). Comics Poetry Beyond 'Squential Art'. IMAGE [\&] Narrative, 15, 106-123.

Bohn, W. (2013). Reading Visual Poetry. Plymouth: Fairleigh Dickinson University Press, 13.

Calligaro, R. (1986). Les aventures de la forme. Cahiers de la Bande Dessinée, 71, 62-64.

Clough, R. (2009). Rhythm \& Rhyme: Asthma, The Blot and Comics-As-Poetry. Recuperado el 1 de febrero de 2019 de https://www.tcj.com/gamma/alternative/rhythmrhymeasthma- the-blot-and-comicsas-poetry 
Collins-Murray, C. (2013). Mapping poetry onto visual arts: Carl Andre's words. Recuperado el 15 de febereo de 2019 de http://www.impossibleobjectsmarfa.com/new-page-42/

Dueben, A. (2012). A Bianca Stone Interview. Recuperado el 1 de febrero de 2019 de http://www.tcj.com/a-bianca-stone-interview

Harguindey, B (2017). Nuevas estructuras. Recuperado el 15 de febrero de 2019 de https://www.13millonesdenaves.com/nuevasestructuras/

McCloud, S. (1993). Understanding Comics: The Invisible Art. New York: Harper Perennial.

McHale, B. (2010). Narrativity and Segmentivity, or, Poetry in the Gutter. En M. Grishakova y M.L. Ryan (eds.), Intermediality and Storytelling (27-48). Berlin: Walter de Gruyter.

Molotiu, A (2009). Abstract Comics: The Anthology: 1967-2009. Seattle: Fantagraphics Books.

Surdiacourt, S (2012). Graphic Poetry: An (im)possible form?. Recuperado el 1 de febrero de 2019 de https://comicsforum.org/2012/06/21/image-narrative-5-graphic-poetry-an-impossible-form-by-steven-surdiacourt/

Vilches, G. (2017). Nuevas estructuras, de Begoña García-Alén. Recuperado el 15 de febrero de 2019 de https://thewatcherblog.wordpress.com/2017/03/22/nuevas-estructuras-de-begonagarcia-alen/ 